\title{
Assessment of Autism Across the Lifespan: A Way Forward
}

\author{
Cheryl Klaiman • Samuel Fernandez-Carriba • Christine Hall • \\ Celine Saulnier
}

Published online: 10 December 2014

(C) Springer International Publishing Switzerland 2014

\begin{abstract}
The prevalence of autism spectrum disorders (ASDs) is currently estimated at 1 in 68 individuals in the US (Centers for Disease Control and Prevention (Morb Mortal Wkly Rep 63:1-21, 2014)), and recommendations for screening and best practices for diagnostic evaluations have been formulated in scientific, clinical, and institutional venues, if not successfully implemented. As such, this article reviews the best practices in the field for toddler, school-age and adolescent/adult assessments, describes at-risk symptomatology in toddlers, reviews common co-morbidities to be aware of at each time point, discusses cultural issues with regard to diagnoses, and brings forth new research, particularly with regard to earlier screening and diagnosis.
\end{abstract}

Keywords Autism - Autism spectrum disorders .

Assessment · Evaluation · Infants · Toddlers · School-age ·

Adolescents $\cdot$ Adults $\cdot$ Culture $\cdot$ Screening $\cdot$ Diagnosis

\section{Introduction}

Assessment of autism spectrum disorders (ASDs) is a slowly changing landscape. Over the past decade, new screening and early detection methods have come into play, pushing for earlier identification and making the ascertainment of 'at-risk' symptomatology increasingly important. When considering the importance of making a diagnosis of ASD, the label provides access to services, resources, and a common language that

This article is part of the Topical Collection on Autism Specrtum

C. Klaiman $(\bowtie) \cdot S$. Fernandez-Carriba $\cdot$ C. Hall $\cdot$ C. Saulnier

Marcus Autism Center, Children's Healthcare of Atlanta, 1920

Briarcliff Road, NE, Atlanta, GA 30329, USA

e-mail: Cheryl.klaiman@emory.edu

C. Klaiman $\cdot$ S. Fernandez-Carriba $\cdot$ C. Hall $\cdot$ C. Saulnier

Emory University, School of Medicine, Atlanta, GA, USA parents and individuals can use in order to better understand and navigate their landscape. Early diagnosis also leads to earlier intervention, which results in a better prognosis for the child [ 2 , $3,4,5 \bullet$. Earlier intervention may also prevent associated symptomatology such as aggression, behavioral dysregulation, anxiety and depression [6-8], may reduce family stressors $[9,10]$, and also reduce societal costs [11-13]. As a result, an increasing number of tools have been developed to identify and screen for the disorder. This article provides an overview of the current state of comprehensive evaluations for individuals with, and at risk for, ASD throughout the lifespan, and describes the continued strive for identification as young as possible.

\section{Changes with the Diagnostic and Statistical Manual of Mental Disorders, 5th Edition}

The Diagnostic and Statistical Manual of Mental Disorders, 5th edition (DSM-5) [14] provides standardized criteria that are used by clinicians to diagnose ASDs. Since publication of the DSM 4th edition, text revision (DSM-IV-TR), criteria have moved from three distinct symptom categories to a two-category system, with a more dimensional approach to conceptualizing the spectrum (i.e. rather than having distinct subtypes) [15]. In the DSM-5, Criteria A include deficits in social communication and social interaction, and Criteria B include restricted and repetitive patterns of behavior. Specifiers can indicate the presence of intellectual and/or language impairment, as well as symptom severity. Studies comparing the DSM-IV-TR and DSM-5 classifications show that most individuals who were diagnosed with a pervasive developmental disorder, as per the DSM-IV, also meet the criteria for ASD, as per the DSM-5. However, some studies question whether the DSM-5 accurately ascertains individuals with higher functioning ASD (i.e. without comorbid cognitive impairment) [16-18]. 


\section{Early Screening and Detection}

\section{Clinical Assessment Measures}

Given that autism can be reliably diagnosed by experienced clinicians by the age of 2 years [19], and that parents typically express concern about their child's development as early as 12 months of age [20-22], it is astonishing that the average age of diagnosis in the US continues to be well over $4 \frac{1}{2}$ years [23]. Moreover, despite the fact that the American Academy of Pediatrics (AAP) currently recommends developmental surveillance and screening for ASD at 18 and 24 months [24], only $28 \%$ of primary care providers routinely use an ASD-specific screening tool [25]. Additionally, when effective screeners are utilized (e.g. the Modified Checklist for Autism in Toddlers, Revised with Follow-up [M-CHAT-R/ F]), only $62 \%$ of children who screened positive followed through with referrals for diagnostic evaluations [26]. Barriers include lack of time to screen and lack of familiarity with screening tools.

Numerous screeners for ASDs are used both clinically and scientifically to identify at-risk infants and toddlers, with the goal being to detect the need for further evaluation rather than to diagnose. The first screening attempt, the Checklist for Autism in Toddlers (CHAT) [27], was developed in the UK in 1992. An elaboration on CHAT - the M-CHAT and the new M-CHAT-R/F - is a similar but extended 23-item parent report checklist that is currently the most commonly used screener for ASDs in primary care settings. Success with the M-CHAT-R/F has shown a reduction in diagnosis of 2 years [26].

The Infant-Toddler Checklist (ITC) [22] is a 24-item parent questionnaire designed to screen for communication delays in children aged 6-24 months. Although it was developed as a broadband screener for general communication delays, it has been validated as a screener for ASDs in children aged 924 months [22]. The most predictive items of the ITC have been used to modify the ITC into an ASD-specific screener known as the Early Screener for Autism and Communication Disorders (ESAC) [28], with validation studies underway.

Several other screening tools include the Early Screening of Autism Traits questionnaire (ESAT) [29], the InfantToddler Social and Emotional Assessment (ITSEA) [30], and the Brief Infant-Toddler Social and Emotional Assessment (BITSEA) [31]. The Screening Tool for Autism in 2year-olds (STAT) $[32,33]$ is a more interactive measure developed to screen for autism in children aged between 24 and 36 months. It was designed for use by community service providers who work with young children in assessment or intervention settings and who have experience with autism. It consists of 12 items and takes about 20 min to administer.

To address some of the limitations of screening tools, Barbaro and Dissanayake [34, 35] studied the effectiveness of a developmental surveillance program where they had maternal and child health nurses and related practitioners assessing children at $8,12,18$, and 24 months for early markers of ASDs, prospectively in a community-based setting. Overall, it was found that when following children prospectively over time, sensitivity, specificity, and positive predictive values were high. Using this approach resulted in earlier identification of children with ASD, as well as the ability to ascertain children with milder symptomatology that otherwise might have been missed.

Although packaged screeners are easy and efficient, research is showing that patterns in developmental profiles that are detected by direct assessment are also predictive of ASD. For instance, delays and deviance in postural and motor development have been linked to ASD in high-risk infants, such as delays in sitting and standing, as well as in the initiation of changes in posture [36]. Item-analyses of the Autism Diagnostic Observation Schedule, 2nd edition, Toddler Module (ADOS-T) [37] show that a combination of limited requesting, imitation skills, and showing behaviors in 12-month-old high-risk infants are predictive of later ASD [38]. Studies also suggest that multiple pathways leading to ASD could exist, with varying profiles of vulnerabilities to observe for $[38,39]$. These findings highlight the need for comprehensive evaluations that include direct testing of infants at risk and at multiple time points in early development.

\section{Experimental Measures}

As behavioral measures continue to be used for the early detection of ASD, experimental technologies are also proving effective in detecting the first signs of ASD - some even before behavioral features are clinically observed.

Several studies have involved eye-tracking paradigms to detect ASD. For instance, using eye-tracking methodologies, Jones and $\mathrm{Klin}\left[40^{\bullet}\right]$ found that high-risk infants (by nature of having an older biological sibling with ASD) who were later diagnosed with ASD themselves have a significant decline in eye fixation between 2 and 6 months of age. The rate of decline during this period of infancy was found to be more predictive of future autism than even the diagnostic measures themselves. In a similar cohort of infants, Shic and colleagues [41] found that eye gaze to faces decreased in infants later diagnosed with ASD only when the presented face was speaking. In a study on older toddlers with ASD between the ages of 14 and 42 months, Pierce and colleagues [42] examined the preference of looking at social images compared with geometric shapes, and found that toddlers with ASD preferred the geometric images significantly more than toddlers without ASD.

Neuroimaging studies are also showing early brain abnormalities in high-risk infants. For instance, aberrant development of white matter fiber tracks has been found between the 
ages of 6 and 24 months in infants later diagnosed with ASD [43•]. Furthermore, these abnormalities have been found to precede and subsequently predict early non-verbal social communication deficits in ASD, such as joint attention [44].

The largest body of literature in the field of autism is focused on genetics. Currently, there is such a strong genetic basis for autism (upwards of 30-40\% of ASD cases yield positive genetic findings) that the American College of Medical Genetics and Genomics Practice Guidelines recommend discussing the need for genetics testing for all individuals with ASD [45]. Despite these incredible strides, efforts to identify specific biomarkers of ASD are still in the preliminary stages. As such, the potential implications on parents to make decisions regarding family planning raise important bioethical questions that need to be further studied [46]. Nevertheless, practitioners need to be well informed of these issues so that they can help families cope with diagnostic information and effectively navigate options for care - which has resulted in an increased need for genetics counseling in the field [47].

\section{Comprehensive Developmental Evaluations}

While screeners often rely heavily on parent report, a comprehensive evaluation should also include direct observation and interaction with the child. The gold-standard assessment is the Autism Diagnostic Observation Schedule, 2nd edition (ADOS) [37, 48], which includes five different modules based on age and language level. The ADOS takes about 45 min to administer and places the child in naturalistic social situations that elicit specific social and communicative reactions. The Toddler Module [37] can be conducted in children aged 1230 months. For younger infants, the Autism Observation Scale for Infants (AOSI) [49] can be used between 6 and 18 months.

An additional critical component to any diagnostic evaluation is conducting a thorough developmental history. This entails inquiring about pregnancy, pre-, peri- and postnatal delivery, early developmental milestones, feeding, sleep, and behavioral patterns, and medical and family history. The most comprehensive measure that assesses for historical patterns of behavior pertinent to ASD is the Autism Diagnostic Interview-Revised (ADI-R) [50], a semi-structured interview that is keyed into the DSM-IV diagnostic criteria for autism. Due to the lengthy nature of the interview and in-depth training required to code each item, the ADI-R is often limited to research use. In fact, the ADI-R [50] and ADOS [51] are used in fewer than $0.1 \%$ and $2.1 \%$, respectively, of diagnostic evaluations for ASD [52]. Lesser quality (i.e. inferior to the gold-standard instruments) instruments, such as parent questionnaires and checklists, are used in only $30 \%$ of such evaluations [52], while the remainder of diagnostic evaluations for ASD - more than $67 \%$ of all such evaluations - use no standardized or validated instruments. The usage of goldstandard instruments is confined to specialty clinics with limited patient capacity.

Best-practice guidelines for comprehensive diagnostic evaluation also call for standardized assessments of the child's cognitive functioning, adaptive, and language skills [53], regardless of the age at which they present for the evaluation. Profiles of strengths and weaknesses are imperative, both to inform the diagnosis and to make appropriate treatment and intervention recommendations. For children with ASD, the clinical presentation is striking in regard to variable profiles both within and across domains, as well as throughout the course of life. It is thus essential to evaluate profiles of behaviors across the lifespan, particularly at pivotal stages of development. With each age group there are important things to consider in undertaking a diagnostic evaluation. These are described in the sections below.

\section{Infants and Toddlers}

In younger children, it is important to assess for the absence of or delay in developmental milestones that would be expected at a given age, along with the emergence of autism symptomatology. To assess developmental profiles, the Mullen Scales of Early Learning [54] and the Bayley Scales of Infant Development, 3rd edition [55] are the most commonly used instruments that typically evaluate areas of receptive and expressive language, fine and gross motor skills, and conceptual or nonverbal reasoning. For evaluating speech, language, and communication in young children, there are a host of instruments, including the Communication and Symbolic Behavior Scales, Developmental Profile (CSBS-DP) [56], which specifically assesses social communication and symbolic play skills for children aged between 6 and 24 months, and the Preschool Language Scale, 5th edition (PLS-5) [57], which measures auditory comprehension and expressive communication from birth through 7 years 11 months. All instruments generally provide an overall standard score that gives a general picture of a child's abilities, along with subdomain scores that elucidate specific strengths and weaknesses.

At-risk behaviors for ASD in infancy include the absence of joint attention, pointing, and gaze following. These behaviors usually develop between 9 and 14 months of age in typical development and thus are only of concern when they have not appeared after this age [58]. If a child exhibits developmental and/or speech delays, the absence or delays in social communication need to be considered in line with mental age. A recent study highlighted several behavioral features that are more likely to indicate the need for autismspecific intervention [59•]. These include visual peering/ examination of objects or clutching objects in their hands for extended periods of time, and not sharing their interest in these 
objects with others. At-risk non-verbal communication skills include limited showing, pointing and responding to name, and limited range and frequency of eye gaze, gesture, and facial expressions. Limited vocalizations (e.g. babbling or jabbering) certainly raise concern, particularly if the vocalizations are not directed at, and reciprocal with, another person, and if they are not well integrated with eye gaze, gestures, and facial expressions.

An additional standard component of a diagnostic evaluation is the assessment of adaptive or 'real-life' skills. Measures of adaptive functioning, such as the Vineland Adaptive Behavior Scales, 2nd edition (Vineland-II) [60], or the Adaptive Behavior Assessment System, 2nd edition (ABAS-II) [61], generally examine functional communication, socialization, daily living, and motor skills. Research has repeatedly shown that individuals with ASD have significant challenges in successfully translating their repertoire of conceptual/ language skills to functional, daily routines (e.g. Klin et al. [62] and Kanne et al. [63]) and that deficits in adaptive skills - particularly in socialization - can be evident in children with ASD as early as 2 years of age (e.g. Paul et al. [64] and Ventola et al. [65].

ASDs are associated with highly variable levels of language, developmental, and conceptual functioning that span from severely delayed and/or non-verbal to intellectually gifted and/or verbally precocious. This variability increases the challenge of early identification, particularly in making differential diagnoses between language and/or developmental delays and ASD, and between ASD and the social vulnerabilities that come with precocious development. Oftentimes, there is a need for giving a provisional diagnosis of ASD in infants and toddlers that requires close monitoring and re-evaluation over time.

\section{School-Age Children}

Autism symptomatology in school-age children tends to be more readily identifiable than in young childhood as the gap between age and social difficulties has typically widened, such that parents, teachers, and others who are involved in the day-to-day life of the child are overtly concerned. Evaluations continue to involve assessment of a child's speech, language, communication, social, intellectual, behavioral, and adaptive functioning, both through direct testing and gathering of developmental and present educational history. In addition, other components of an evaluation might be necessary in order to rule out potential learning disabilities, attentional disabilities, difficulties with executive functioning, behavioral challenges, and the like. A skilled clinician should evaluate the child and make assessment decisions as necessary as an evaluation proceeds.

School-age individuals with ASD can also exhibit an increase in learning difficulties, behavioral regulation, and emotional symptomatology. Learning challenges tend to become most apparent as children segue from rote, concrete learning to more conceptual and abstract learning. Common comorbidities include hyperlexia, non-verbal learning disability, or specific learning disorders (e.g. mathematics, written expression). Behavioral challenges (e.g. aggression, tantrums, melt-downs, self-injury) typically emerge as the result of an inability to effectively communicate one's needs and wants, making it imperative to conduct functional behavior assessments to identify behavioral triggers and subsequently teach more functional skills. Anxiety tends to be markedly common as individuals with ASD struggle to navigate an extremely social world (e.g. having to tolerate transitions, changes in routines, social demands, etc.). They can also have atypical reactions to environmental stimuli (e.g. specific fears and phobias, obsessive compulsive behaviors, generalized anxiety). Psychotropic medications can be effective in alleviating these symptoms [66]. In the absence of treatment, these challenges can set-up individuals with ASD for failed experiences that may result in depressive symptoms and even suicidality, particularly during the later school-age years and into adolescence and adulthood [67].

Difficulties with attention, hyperactivity, and emotion regulation are also commonly observed in school-aged individuals with ASD. On standardized rating scales, at least onethird of individuals with ASD also meet the criteria for a diagnosis of attention-deficit hyperactivity disorder (ADHD) $[68,69]$. On assessments of disruptive behavior, research has found that up to $60 \%$ of individuals show self-injurious, aggressive, oppositional, disruptive, and destructive behaviors [70-72]. Importantly, there are a subset of individuals who exhibit behaviors that pose more serious safety concerns, including elopement, self-injury, and pica [73-76].

The DSM-5 now stipulates that individuals with ASD can carry a dual diagnosis of ASD and ADHD. Thus, this comorbid diagnosis signifies that the symptoms of inattention, impulsivity, and/or hyperactivity are above and beyond what would be expected for ASD, and that specific intervention strategies to address these comorbid behaviors could be indicated.

\section{Adolescents and Adults}

Despite the fact that ASD is a neurodevelopmental disorder that emerges in the first few years of life, and despite the strides made in early detection and identification of the disorder, many adults remain unidentified as having ASD and/or they have been misidentified with other diagnostic labels throughout their childhood. However, requests for adolescent/adult evaluations can also revolve around addressing a specific need or providing updated information for continued services (e.g. transition to adulthood, planning for 
college or post-secondary education, identifying legal guardianship post-age of majority, eligibility for state services, etc.).

Current research shows that the majority of individuals with ASD have intellectual abilities in the average to aboveaverage range $[1 \bullet \cdot$ and should therefore have the capacity to be independent adults. However, research on adult outcome in ASD indicates that more than $50 \%$ of adults fail to achieve levels of independent employment, living, and self-care, and fail to establish meaningful social relationships [77-79]. They may possess the skills to perform a job successfully but they get into trouble in the work or community environment which demands a modicum of social ability to successfully navigate. Moreover, adolescents and adults with ASD can be vulnerable to being victimized due to their social naiveté and limited insight into, or awareness of, social nuances. For example, they might not be aware of solicitations (in person or via the Internet); they may not comprehend sarcasm, figures of speech, or teasing; and they could have inappropriate circumscribed or restricted interests that get them into legal trouble. For these reasons, it becomes all the more imperative to include assessments of adaptive functioning and social/ emotional awareness into the diagnostic evaluation process, and to ensure that strategies to enhance functional social and daily life skills are explicitly taught.

Consistent with school-age and adolescent individuals, research has shown high rates of comorbid conditions, including anxiety disorders, depressive disorders, and ADHD in adults with ASD [80]. Previous studies have shown that between 11 and $30 \%$ of adolescents with ASD also meet the criteria for major depressive disorders [81-83], and estimates of comorbid anxiety disorders range from 43 to $84 \%$ [81, 83-85]. While schizophrenia and autism are two distinct disorders, there is also a subset of individuals with autism who begin to demonstrate psychotic symptoms in adolescence or early adulthood [86], although the true rate of comorbid psychosis is difficult to establish, for a couple of reasons. First, there is some symptom overlap, particularly between autism and the prodromal state of schizophrenia, which involves worsening symptoms of social withdrawal, poor eye contact, and communication difficulties [87]. Second, common ASD symptoms of rigidity and difficulty shifting set can be misinterpreted as paranoia and thought disorder, sometimes resulting in a misdiagnosis of schizophrenia in individuals with autism [88] (see also Hofvander et al. [80] and Raja and Azzoni [89]). Thus, to correctly distinguish ASD from emerging thought disorder, or to determine if both conditions are co-occurring, it is particularly important to learn as much as possible regarding early developmental history and the developmental course of symptoms over time.

Recent studies have also highlighted comorbid catatonia syndrome in individuals with ASD [90]. The DSM-5 reflects a wider view of catatonia as a condition that is not only associated with schizophrenia but one that can also occur with other psychiatric and medical conditions. Wing and Shah [91] found that individuals with co-occurring ASD and catatonia showed particular characteristic symptoms, such as difficulty initiating movements, increased passivity, a worsening of ritualistic and repetitive behaviors, and the reversal of day and night. While it is now recognized that catatonia can co-occur with ASD, there are also many symptoms of catatonia that can be misinterpreted as ASD symptoms, including mutism, stereotypic speech, repetitive behaviors, echolalia, posturing, mannerisms, purposeless agitation, and rigidity [90]. Again, obtaining a good understanding of the age of onset and course of these symptoms is critical for making the differential diagnosis between these two conditions, as well as determining whether they are comorbid conditions.

\section{Cultural Disparities in Assessment and Diagnosis of Autism Spectrum Disorders}

As noted previously, the enormous variability in human development contributes to the large heterogeneity in ASD symptomatology. Given the fact that current diagnosis does not come from biological or genetic assessments but from interpretative clinical judgment based on observation and a developmental history review, healthcare practices, as well as cultural differences between families and providers, may also have an influence on assessment and characterization.

No significant differences in ASD symptomatology related to social deficits have been reported when comparing individuals from different countries [92] or different groups within a country [93•]. However, differences do exist in overall identification and level of cognitive functioning. There is a higher prevalence of ASD in White individuals compared with other racial and ethnic groups in the US $[1 \bullet \bullet, 94,95]$. According to recent studies, these differences do not always translate into group differences in the age of diagnosis $[1 \bullet \bullet, 96 \bullet$, highlighting that misdiagnosis or lack of diagnosis in minorities is even a greater problem than delayed identification.

Racial and ethnic differences in the US mostly affect children without cognitive delays $[1 \bullet \bullet, 97]$ from families with a lower socioeconomic status [98•], i.e. there are no racial/ ethnic differences in higher socioeconomic strata and no differences in prevalence of ASD with co-occurring cognitive delays. Therefore, ASD with intellectual disabilities accounts for most of the ASD diagnoses in racial/ethnic minorities [93•, 97, 99]. Finally, there is also a well-documented association between socioeconomic status and higher prevalence and lower age of diagnosis in the US [97, 100, 101], with children from geographical areas comprised of adults with higher education and family incomes being diagnosed more frequently and earlier. Again, this association only holds for children without cognitive delays [98]. The direction of the socioeconomic gradient for ASD identification is the opposite 
in other countries such as Sweden that have nearly universal access to healthcare, where prevalence of ASD (but also ASD with co-occurring cognitive delays) is higher in immigrant populations [102].

In most developmental conditions the greatest source of differences is socioeconomic rather than racial or ethnic [103], and ASD seems to be no different. It remains a distinct condition, with a strong genetic component and probably universal symptomatology related to social functioning. However, factors such as family income, maternal education, rural/ urban origin, and immigration status, as well as their interaction with associated features such as cognitive functioning, cannot be ignored in the assessment of ASD throughout the lifespan, nor the fact that there are indeed racial/ethnic disparities in lower socioeconomic strata, at least in the US. In addition to public health efforts to make services more accessible for all, and relevant to this paper, the socioeconomic sensitivity of assessment instruments and the cultural competence of providers warrant much attention. As Cuccaro and colleagues [104] elegantly demonstrated, there may be a clinician bias when diagnosing two children with exactly the same symptoms, depending on their socioeconomic background. There is indeed a great need for research in this area that guides truly accurate and universal assessment of ASDs.

\section{Conclusions}

ASD is a complex neurodevelopmental disorder that, for the majority of individuals, impacts the lifespan. Assessment of ASD is therefore not merely making a one-time diagnosis; the needs of children with ASD, as with all children, change as they develop over time, thus requiring monitoring and reevaluation throughout life. Clinicians need to not only have expertise in ASD symptomatology but also possess different sets of knowledge necessary at each stage of developmentfrom knowledge of early infant and toddler development, to understanding the complexities of school-age children, adolescents, and adults.

As the majority of adults with ASD struggle with the burdens of a multitude of associated symptomatology, the field is pushing for the earliest means of detection with the hope of ameliorating the potentially debilitating features that come with having a social disability. With this comes the push for investigations of new screening and diagnostic procedures that can effectively ascertain individuals across all racial, ethnic, and socioeconomic barriers, as well as the need for research on effective early interventions, because diagnosis and subsequent treatment must work in concert in order to truly benefit children and families. As the field moves forward, our hope is to maximize the potential of every individual with ASD so that assessment becomes more about ability rather than disability.

\section{Compliance with Ethics Guidelines}

Conflict of Interest Cheryl Klaiman, Samuel Fernandez-Carriba, Christine Hall, and Celine Saulnier declare that they have no conflict of interest.

Human and Animal Rights and Informed Consent This article does not contain any studies with human or animal subjects, performed by any of the authors.

\section{References}

Papers of particular interest, published recently, have been highlighted as:

- Of importance

•• Of major importance

1.• Centers for Disease Control and Prevention. Prevalence of autism spectrum disorder among children aged 8 years - autism and developmental disabilities monitoring network, 11 sites, United States. Morb Mortal Wkly Rep. 2014;63:1-21. This is the most current report of ASD prevalence in children aged 8 years in the US, including sociodemographic variables and data on cognitive functioning.

2. Warren Z, McPheeters M, Sathe N, et al. A systematic review of early intensive intervention for autism spectrum disorders. Pediatrics. 2011;127:e1303-11. This article provides a comprehensive review of the outcomes for early interventions for very young children with ASD. This study found evidence that early behavioral and developmental interventions are associated with improvements in cognitive abilities, language, and adaptive skills in some young children with ASDs.

3. Dawson G, Rogers S, Munson J, et al. Randomized, controlled trial of an intervention for toddlers with autism: the early start Denver model. Pediatrics. 2010;125:e17-23.

4. Zwaigenbaum L, Bryson S, Garon N. Early identification of autism spectrum disorders. Behav Brain Res. 2013;251: 133-46.

5. Dawson G, Jones E, Merkle K, et al. Early behavioral intervention is associated with normalized brain activity in young children with autism. J Am Acad Child Adolesc Psychiatry. 2012;51:1150-9. This article nicely demonstrates the plasticity of the brain when intervention is implemented at an early age. Makes a strong argument for earlier detection.

6. Dawson G. Early behavioral intervention, brain plasticity, and the prevention of autism spectrum disorder. Dev Psychopathol. 2008;20:775-803.

7. Mundy P, Sullivan L, Mastergeorge AM. A parallel and distributed-processing model of joint attention, social cognition and autism. Autism Res. 2009;2:2-21.

8. Reichow B, Barton EE, Boyd BA, Hume K. Early intensive behavioral intervention (EIBI) for young children with autism spectrum disorders (ASD). Cochrane Database Syst Rev. 2012;10, CD009260.

9. Renty J, Roeyers H. Satisfaction with formal support and education for children with autism spectrum disorder: the voices of the parents. Child Care Health Dev. 2006;32:371-85.

10. Hall HR, Graff JC. Maladaptive behaviors of children with autism: parent support, stress, and coping. Issues Compr Pediatr Nurs. 2012;35:194-214.

11. Peters-Scheffer N, Didden R, Korzilius H, Matson J. Cost comparison of early intensive behavioral intervention and treatment as 
usual for children with autism spectrum disorder in The Netherlands. Res Dev Disabil. 2012;33:1763-72.

12. Jarbrink K. The economic consequences of autistic spectrum disorder among children in a Swedish municipality. Autism. 2007;11:453-63.

13. Sanchez-Valle E, Posada M, Villaverde-Hueso A, et al. Estimating the burden of disease for autism spectrum disorders in Spain in 2003. Autism Dev Disabil. 2008;38:288-96.

14. American Psychiatric Association. Diagnostic and statistical manual of mental disorders. 5th ed. Washington, DC: American Psyciatric Publishing; 2013.

15. Ousley O, Cermak T. Autism spectrum disorder: defining dimensions and subgroups. Curr Dev Disord Rep. 2014;1:20-8.

16. McPartland JC, Reichow B, Volkmar FR. Sensititivity and specificity of proposed DSM-5 diagnostic criteria for autism spectrum disorder. J Am Acad Child Adolesc Psychiatry. 2012;51:368-83.

17. Matson JL, Hattier MA, Williams LW. How does relaxing the algorithm for autism affect DSM-V prevalence rates? J Autism Dev Disord. 2012;42:1549-56.

18. Kulage KM, Smaldone AM, Cohn EG. How will DSM-5 affect autism diagnosis? A systematic literature review and meta-analysis. J Autism Dev Disord. 2014;44:1918-32.

19. Chawarska K, Klin A, Paul R, Macari S, Volkmar F. A prospective study of toddlers with ASD: short-term diagnostic and cognitive outcomes. J Child Psychol Psychiatry. 2009;50:1235-45.

20. Chawarska K, Paul R, Klin, A, et al. Parental recognition of developmental problems in toddlers with autism spectrum disorders. J Autism Dev Disord. 2007;37:62-72.

21. Young RL, Brewer N, Pattison C. Parental identification of early behavioural abnormalities in children with autistic disorder. Autism. 2003;7:125-43.

22. Wetherby AM, Brosnan-Maddox S, Peace V, Newton L. Validation of the infant-toddler checklist as a broadband screener for autism spectrum disorders from 9 to 24 months of age. Autism. 2008;12:487-511.

23. Shattuck PT, Durkin M, Maenner, M, et al. Timing of identification among children with an autism spectrum disoder: findings from a population-based surveillance study. J Am Acad Child Adolesc Psychiatry. 2009;48:474-83.

24. Johnson CP, Myers SM. Identification and evaluation of children with autism spectrum disorders. Pediatrics. 2007;120:1183-215.

25. Gillis JM. Screening practices of family physicians and pediatricians in 2 southern states. Infants Young Child. 2009;22:321-30.

26. Robins DL, Casagrande K, Barton M, et al. Validation of the modified checklist for autism in toddlers, revised with follow-up (M-CHAT-R/F). Pediatrics. 2014;133:37-45.

27. Baron-Cohen S, Allen J, Gillberg C. Can autism be detected at 18 months? The needle, the haystack, and the CHAT. Br J Psychiatry. 1992;161:839-43.

28. Wetherby AM, et al. The early screening for autism and communication disorders: preliminary field-testing of an autism-specific screening tool for children 12 to 36 months of age. International Meeting for Autism Research. Chicago, IL, May 7-9, 2009.

29. Dietz C, Swinkels S, Daalen E, Engeland H, Buitelaar J. Screening for autistic spectrum disorder in children aged 14-15 months: population screening with the early screening of autistic traits questionnaire (ESAT). J Autism Dev Disord. 2006;36:713-22.

30. Carter A, Briggs-Gowan M. Infant toddler social emotional assessment (ITSEA). San Antonio, TX, Pearson. 2006.

31. Briggs-Gowan $\mathrm{M}$, Carter A. brief infant toddler social emotional assessment (BITSEA). San Antonio, TX, Pearson. 2006.

32. Stone WL, Coonrod EE, Ousley OY. Brief report: screening tool for autism in two-year-olds (STAT): development and preliminary data. J Autism Dev Disord. 2000;30:607-12.

33. Stone WL, McMahon CR, Henderson LM. Use of the screening tool for autism in two-year-olds (STAT) for children under 24 months: an exploratory study. Autism. 2008;12:557-73.
34. Barbaro J, Dissanayake C. Early markers of autism spectrum disorders in infants and toddlers prospectively identified in the social attention and communication study. Autism. 2013;17:64-86.

35. Barbaro J, Dissanayake C. Prospective identification of autism spectrum disorders in infancy and toddlerhood using developmental surveillance: the social attention and communication study. $\mathrm{J}$ Dev Behav Pediatr. 2010;31:376-85.

36. Nickel LR, Thatcher AR, Keller F, Wozniak RH, Iverson JM. Posture development in infants at heightened vs. low risk for autism spectrum disorders. Infancy. 2013;18:639-61.

37. Lord C, Luyster RJ, Gotham K, Guthrie W. Autism Diagnostic Observation Schedule, Toddler Module. Torrance: Western Psychological Services; 2012.

38. Macari SL, Campbell D, Gengoux, G, et al. Predicting developmental status from 12 to 24 months in infants at risk for autism spectrum disorder: a preliminary report. J Autism Dev Disord. 2012;42:2636-47.

39. Landa RJ, Gross AL, Stuart EA, Bauman M. Latent class analysis of early developmental trajectory in baby siblings of children with autism. J Child Psychol Psychiatry. 2012;53:989-96.

40. Jones W, Klin A. Attention to eyes is present but in decline in 2-6month-old infants later diagnosed with autism. Nature. 2014;504: 427-31. This study marks the earliest known indicators of social disability in infancy, and also demonstrates that in infants later diagnosed with ASD, eye looking is normative at 2 months of age but then declines between 2 and 6 months. The fact that eye fixation declines, rather than being absent initially, has promising implications for the potential of early intervention.

41. Shic F, Macari S, Chawarska K. Speech disturbs face scanning in 6-month-old infants who develop autism spectrum disorder. Biol Psychiatry. 2014;75:231-7.

42. Pierce K, Conant D, Hazin R, Stoner R, Desmond J. Preference for geometric patterns early in life as a risk factor for autism. Arch Gen Psychiatry. 2011;68:101-9.

43. Wolff JJ, Gu H, Gerig G, et al. Differences in white matter fiber tract development present from 6 to 24 months in infants with autism. Am J Psychiatry. 2012;169:589-600. The results showed aberrant development of white matter pathways in infants who were later diagnosed with ASD. These findings suggest that dynamic changes in the brain may precede the behavioral manifestations of ASD.

44. Elison JT, Wolff J, Heimer D, et al. Frontolimbic neural circuitry at 6 months predicts individual differences in joint attention at 9 months. Dev Sci. 2013;16:186-97.

45. Schaefer GB, Mendelsohn NJ. Clinical genetics evaluation in identifying the etiology of autism spectrum disorders: 2013 guideline revisions. Genet Med. 2013;15:399-407.

46. Voineagu I, Yoo HJ. Current progress and challenges in the search for autism biomarkers. Dis Markers. 2013;1:55-65.

47. McMahon WM, Baty BJ, Botkin J. Genetic counseling and ethical issues for autism. Am J Med Genet C: Semin Med Genet. 2006;142C:52-7.

48. Lord C, Rutter M, DiLavore PC, et al. Autism diagnostic observation schedule modules 1-4. Torrace: Western Psychological Services; 2012.

49. Bryson SE, Zwaigenbaum L, McDermott C, Rombough V, Brian $\mathrm{J}$. The autism observation scale for infants: scale develoment and reliability data. J Autism Dev Disord. 2008;38:731-8.

50. Rutter M, Le Couteur A, Lord C. ADI-R: autism diagnostic interview-revised. Torrace: Western Psychological Services; 2003.

51. Lord C, Rutter M, DiLavore P, Risi S. Autism diagnostic observation schedule. Torrance: Western Psychological Services; 1999.

52. Wiggins LD, Baio J, Rice C. Examination of the time between first evaluation and first autism spectrum diagnosis in a populationbased sample. J Dev Behav Pediatr. 2006;27:S79-87.

53. Filipek PA, Accardo P, Ashwal S, et al. Practice parameter: screening and diagnosis of autism. Report of the quality standards 
subcommittee of the American Academy of Neurology and the Child Neurology Society. Neurology. 2000;55:468-79.

54. Mullen EM. Mullen scales of early learning. Circle Pines: American Guidance Services, Inc.; 1995.

55. Bayley N. bayley scales of infant and toddler development. PsychCorp; 2006.

56. Prizant BM, Wetherby AM. Communication and symbolic behavior scales developmental profile (CSBS DP). Baltimore: Brookes Publishing; 2002.

57. Zimmerman IL, Steiner VG, Pond RE. Preschool language Scale, 5th ed. (PLS-5). San Antonio, TX, Pearson. 2011.

58. Johnson CP. Recognition of autism before age 2 years. Pediatr Rev. 2008;29:86-96.

59. Estes A, Vismara L, Mercado C, et al. The impact of parentdelivered intervention on parents of very young children with autism. J Autism Dev Disord. 2014;44:353-65. Although this was a small, open-label study, the article starts the dialogue of how early signs and symptoms of ASD can be recognized as young as 12 months of age, and the possible benefits of early intervention.

60. Sparrow SS, Cicchetti DV, Balla DA. Vineland adaptive behavior scales, 2nd ed (Vineland II). San Antonio, TX, Pearson. 2005.

61. Harrison P, Oakland T. Adaptive behavior assessment system, 2nd ed. San Antonio, TX, Pearson. 2003.

62. Klin A, Saulnier C, Sparrow S, et al. Social and communication abilities and disabilities in higher functioning individuals with autism spectrum disorders: the Vineland and the ADOS. J Autism Dev Disord. 2007;37:748-59.

63. Kanne SM, Gerber A, Quirmbach L, et al. The role of adaptive behavior in autism spectrum disorders: implications for functional outcome. J Autism Dev Disord. 2011;41:1007-18.

64. Paul R, Loomis R, Chawarska K. Adaptive behavior in toddlers under two with autism spectrum disorders. J Autism Dev Disord. 2014;44:264-70.

65. Ventola PE, Saulnier CA, Steinberg E, Chawarska K, Klin A. Early-emerging social adaptive skills in toddlers with autism spectrum disorders: an item analysis. J Autism Dev Disord. 2014;44:283-93.

66. Coury DL, Anagnostou E, Manning-Courtney P, et al. Use of psychotropic medicaiton in children and adolescents with autism spectrum disorders. Pediatrics. 2012;130:S69-76.

67. Shtayermann O. Peer victimization in adolescents and young adults diagnosed with Asperger syndrome: a link to depressive symptomatology, anxiety symptomatology, and suicidal ideation. Issues Compr Pediatr Nurs. 2007;30:87-107.

68. Gadow KD, DeVincent CJ, Pomeroy J. ADHD symtpom subtypes in children with pervasive developmental disorder. J Autism Dev Disord. 2006;36:271-83.

69. Ghanizadeh A. Co-morbidity and factor analysis on attention deficit hyperactivity disorder and autism specrum disorder DSM-IV-derived items. J Res Med Sci. 2012;17:368-72.

70. Goldin RL, Matson JL, Tureck K, Cervantes PE, Jang J. A comparison of tantrum behavior profiles in children with ASD, ADHD and comorbid ASD and ADHD. Res Dev Disabil. 2013;34:2669-75.

71. Guttmann-Steinmetz S, Gadow KD, DeVincent CJ. Oppositional defiant and conduct disorder behaviors in boys with autism spectrum disorder with and without attention-deficit hyperactivity disorder versus several comparison samples. J Autism Dev Disord. 2009;39:976-85.

72. Gadow KD, DeVincent CJ, Drabick DA. Oppositional defiant disorder as a clinical phenotype in children with autism spectrum disorder. J Autism Dev Disord. 2008;38:1302-10.

73. Anderson C, Law J, Daniels A, et al. Occurrence and family impact of elopement in children with autism spectrum disorders. Pediatrics. 2012;130:870-7.

74. Kinnell HG. Pica as a feature of autism. Br J Psychiatry. 1985;147: $80-2$.
75. Duerden EG, Szatmari P, Roberts SW. Toward a better understanding of self injurious behaviors in children and adolescents with autism spectrum disorders. J Autism Dev Disord. 2012;42: 2515-8.

76. Symons FJ, Thompson A, Rodriguez MC. Self-injurious behavior and the efficacy of naltrexone treatment: a quantitative synthesis. Ment Retard Dev Disabil Res Rev. 2004;10:193-200.

77. Billstedt E, Gillberg IC, Gillberg C, Gillberg C. Autism after adolescence: population-based 13- to 22-year follow-up study of 120 individuals with autism diagnosed in childhood. J Autism Dev Disord. 2005;35:351-60.

78. Eaves LC, Ho HH. Young adult outcome of autism spectrum disorders. J Autism Dev Disord. 2008;38:739-47.

79. Howlin P, Goode S, Hutton J, Rutter M. Adult outcome for children with autism. J Child Psychol Psychiatry. 2004;45:212-29.

80. Hofvander B, Delorme R, Chaste P, et al. Psychiatric and psychosocial problems in adults with normal-intelligence autism spectrum disorders. BMC Psychiatry. 2009;9:35.

81. De Bruin EI, Ferdinand RF, Meester S, de Nijs PFA, Verheij F. High rates of psychiatric co-morbidity in PDD-NOS. J Autism Dev Disord. 2007;37:877-86.

82. Wing L. Asperger's syndrome: a clinical account. Psychol Med. 1981;11:115-29.

83. Leyfer OT, Folstein S, Bacalman S, et al. Comorbid psychiatric disorders in children with autism: interview development and rates of disorders. J Autism Dev Disord. 2006;36:849-61.

84. Muris P, Steerneman P, Mercklebach H, Holdrinet I, Meesters C. Comorbid anxiety symptoms in children with pervasive developmental disorders. J Anxiety Disord. 1998;12:387-93.

85. Sukhodolsky DG, Scahill L, Gadow K, et al. Parent-rated anxiety symptoms in children and pervasive developmental disorders: frequency and association with core autism symptoms and cognitive functioning. J Abnorm Child Psychol. 2008;36:117-28.

86. Khandaker GM, Stochl J, Zammit S, Lewis G, Jones PB. A population-based longitudinal study of childhood neurodevelopmetnal disorders, IQ and subsequent risk of psychotic experiences in adolescence. Psychol Med. 2014;44:3229-38.

87. Fusar-Poli P, Borgwardt S, Bechdolf A, et al. The psychosis highrisk state: a comprehensive state-of-the-art review. JAMA Psychiatr. 2013;70:107-20.

88. Konstantareas MM, Hewitt T. Autistic disorder and schizophrenia: diagnostic overlaps. J Autism Dev Disord. 2001;31:19-28.

89. Raja M, Azzoni A. Autistic spectrum disorders and schizophrenia in the adult psychiatric setting: diagnosis and comorbidity. Psychiatr Danub. 2010;22:514-21.

90. Mazzone L, Postorino V, Valeri G, Vicari S. Catatonia in patients with autism: prevalence and management. CNS Drugs. 2014;28: 205-15.

91. Wing L, Shah A. Catatonia in autistic spectrum disorders. Br J Psychiatry. 2000;176:357-62.

92. Matson JL, Worley J, Fodstad JC, et al. A multinational study examining the cross cultural differences in reported symptoms of autism spectrum disorders: Israel, South Korea, the United Kingdom, and the United States of America. Res Autism Spectr Disord. 2011;5:1598-604.

93. Chaidez V, Hansen RL, Hertz-Picciotto I. Autism spectrum disorders in Hispanics and non-Hispanics. Autism. 2012;16:381-97. This is the only study, as far as we know, that compares ASD symptomatology in young children (ages 2-5 years) from two ethnic groups in the US. The only differences in the two populations were in language and overall cognitive functioning.

94. Centers for Disease Control and Prevention. CDC health disparities and inequalities report - United States, 2011. Morb Mortal Wkly Rep. 2011;60:1-113.

95. Centers for Disease Control and Prevention. Prevalence of autism spectrum disorders: autism and developmental disabilities 
monitoring network, 14 sites, United States, 2008. Morb Mortal Wkly Rep. 2012;6:1-18.

96. Daniels AM, Mandell DS. Explaining differences in age at autism spectrum disorder diagnosis: a critical review. Autism. 2013;18: 583-97. The most recent review of findings on disparities related to age of first ASD diagnosis in different cultural, socioeconomic, and racial/ethnic groups in the US and internationally.

97. Bhasin TK, Schendel D. Sociodemographic risk factros for autism in a US metropolitan area. J Autism Dev Disord. 2007;37:667-77.

98. Durkin MS, Maenner M, Meaney J, et al. Socioeconomic inequality in the prevalence of autism spectrum disorder: evidence from a U.S. cross-sectional study. PLoS One. 2010;5:e11551. Even though this article was published in 2010, it is unique in that the authors attempted to disentangle race and ethnicity from socioeconomic status, and brought attention to the role of cognitive functioning in this differentiation. They did not observe racial/ethnic differences in higher socioeconomic strata and no racial/ethnic differences in children with lower cognitive level, which the CDC report confirmed 4 years later.
99. Palmer RF, Walker T, Mandell D, Bayles B, Miller CS. Explaining low rates of autism among Hispanic schoolchildren in Texas. Am J Public Health. 2010;100:270-2.

100. Mandell DS, Listerud J, Levy SE, Pinto-Martin JA. Race differences in the age at diagnosis among Medicaid-eligible children with autism. J Am Acad Child Adolesc Psychiatry. 2002;41:1447-53.

101. Croen LA, Grether JK, Selvin S. Descriptive epidemiology of autism in a California population: who is at risk? J Autism Dev Disord. 2002;32:217-24.

102. Magnusson C, Rai D, Goodman A, et al. Migration and autism spectrum disorder: population-based study. Br J Psychiatry. 2012;201:109-15.

103. Duncan GJ, Murnane RJ. Whither opportunity? Rising inequality, schools, and children's life chances. New York: Russell Sage Foundation; 2011.

104. Cuccaro ML, Wright HH, Rownd CV, Abramson RK. Brief report. Professional perceptions of children with developmental disabilities: the influence of race and socioeconomic status. J Autism Dev Disabil. 1996;26:461-9. 